\title{
Are people the key to enabling collaborative smart logistics?
}

Oliver Bates

School of Computing and

Communications

Lancaster University, UK

o.bates@lancaster.ac.uk

Bran Knowles

School of Computing and

Communications

Lancaster University, UK

b.h.knowles1@lancaster.ac.uk

\section{Adrian Friday}

School of Computing and

Communications

Lancaster University, UK

a.friday@lancaster.ac.uk

Permission to make digital or hard copies of part or all of this work for personal or classroom use is granted without fee provided that copies are not made or distributed for profit or commercial advantage and that copies bear this notice and the full citation on the first page. Copyrights for third-party components of this work must be honored. For all other uses, contact the owner/author(s). Copyright is held by the

author/owner(s).

CHI'17 Extended Abstracts, May 6-11, 2017, Denver, CO, USA.

http://dx.doi.org/10.1145/3027063.3053128

\begin{abstract}
The number of parcels delivered is growing annually, with a

$15.7 \%$ increase to 1 billion parcel deliveries in the UK in 2015. We introduce Freight Traffic Control 2050 which is exploring how to transform last-mile urban freight through "collaborative logistics". Based on our ethnographic

fieldwork, we introduce the context and challenges in this domain. We highlight the value of experience and tacit

knowledge, and the importance of approaching this domain from a socio-technical perspective. We offer a selection of early challenges identified as a starting point for discussion within the $\mathrm{HCl}$ community.
\end{abstract}

\section{Author Keywords}

Smart Logistics; Sustainable Transport; Tacit Knowledge;

Qualitative research

\section{ACM Classification Keywords}

H.5.m [Information interfaces and presentation (e.g., $\mathrm{HCl})$ ]:

Miscellaneous.

\section{Introduction}

The Freight Traffic Control 2050 (FTC 2050) project aims to help transform the energy demands of last-mile urban freight through "collaborative logistics" between freight service providers. The goal is to demonstrate that more efficient use of capacity could be made, reducing the 


\section{Domain Specific Terminology}

Carrier: The company responsible for the contract that ensures the successful pickup and delivery of goods between locations.

Freight Traffic: In the context of this article, road traffic composed of light goods vehicles (LGV) that weigh less than 3.5 tonnes.

Lorry, Van or Wagon: A colloquial UK term for a four wheel light goods vehicle used to deliver parcels and goods in the more narrow streets of European cities.

Last mile delivery: Used to describe deliveries of parcels on the last leg of their journey to the recipient from the local carrier depot. number of vehicles and associated congestion, and improving air quality. Little progress has been made since Deblanc's observations of European urban goods being indifferent to urban structure, having inefficient policies, and slow to move on provisioning [4]. Inline with suggestions outlined by Deblanc, FTC 2050 aims to contribute toward reduced environmental impact of freight transport through smarter scheduling, planning and collaboration as an application of smart and sustainable logistics [3].

Freight transport currently makes up around $16 \%$ of total road vehicle activity in urban environments in the UK [1]. Lorries and vans perform $30 \%$ of their activities in urban areas, causing pollution and congestion, taking parking spaces and competing for kerbside space. In the UK LGV vehicles continues a trend of growth (up 4\% in 2015 from 2014), contributing $13 \%$ of the UK's transport emissions in 2014 [5], rising to $15 \%$ in 2015, with 2015 being the largest growth year in LGV since the 1980s [6].

These issues are likely to grow worse with traffic congestion in Central London is predicted to grow by $60 \%$ by 2030 , with a $20 \%$ growth in the amount of vans contributing to congestion [9]. Overall, the number of parcels delivered annually is expected to continue to grow, with a $15.7 \%$ increase to 1 billion parcel deliveries observed in the UK in 2015 [7]. Online shopping and convenient 'one-click' access to shopping and on-demand services, and low or even zero cost delivery services is accelerating these trends.

To develop our initial understanding of the domain, we combine field observations of delivery drivers working in the city of London during October 2016, interviews and observations of depot staff in the city, and in two distribution hubs at national locations in UK. These observations are supplemented by first analysis of data drawn from daily parcel manifests (September-October 2016); plus vehicle and driver GPS tracks for 3 days in October 2016 during which selected drivers were also accompanied by an observer who recorded stopping locations and how parcels and IT systems were handled.

In this short paper we unpack some of the early challenges and opportunities in realising collaboration between service providers we have observed-service providers who are currently operating in potentially overlapping routes and services, and competing and differentiating themselves from one another. We raise several points where we believe the $\mathrm{HCl}$ community can take a lead in helping make a contribution in this important and fast changing domain.

\section{Freight Traffic}

Although a service many of us take for granted, it is worth setting out some of the detail and assumptions regarding freight (and specifically parcel and courier services), as we currently understand them.

From a high level perspective, the flow of freight traffic is dictated by how, where and when logistics companies pick up and deliver parcels to and from their customers.

Customers (e.g. business, domestic) generally require their parcels to get from one location (e.g. a business premises, domestic address) to another. A contract is made with a logistics company by the customer, and this guarantees that the parcel will get from the sender to the recipient. The parcel will typically be picked up from a local address to a local depot (sometimes dropped off at local depot). The parcels are then transported by the carriers' national network to a more local depot (sometimes via other depots) - a process known as trunking —and is then delivered to recipient.

At each depot the parcel goes through sorting and is loaded onto a vehicle that takes it nearer its end location. Every 


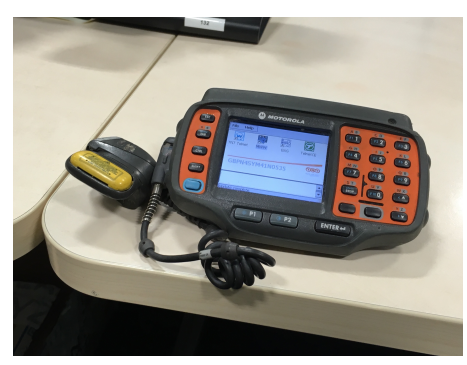

Figure 1. Technology in freight transport is critical, but with the use of closed and often legacy commercial systems there are challenges when intervening. parcel passes through a minimum of one depot between sender and recipient. The responsibilities surround picking up parcels, their sorting, and ensuring timely deliveries falls into the hands of the employees who drive freight vehicles and work in the carrier depots. Additional work is required at the depot to ensure that vehicles are not over capacity, or are suitable for particularly large or awkward loads. The order that parcels are loaded onto the vehicle to optimise access on route is one of the critical factors affecting delivery performance. Collections often have to be worked in with delivery during a round, which can lead to drivers having to backtrack or go out of their way.

Not all services are the same. Whilst we may take parcel services for granted (e.g. Amazon's Amazon Prime bundle, free next delivery options, free return policies), the non-stop processes and complex networks of carriers operating internationally ensure that parcels get from $A$ to $B$ in accordance with the service level agreements (e.g. guaranteed next day delivery, specific delivery slots) that are purchased by customers. These services and expectations to a large extent drive the timing of parcel handling and delivery. In fact, the unique selling points (USPs) and products of couriers and delivery companies have been purposely developed to ensure that each different company can have relevance in the market. These USPs have lead to carriers distinguishing themselves by promising service level agreements (SLAs) that are more appealing to particularly clients (e.g. premium next day deliveries, picking delivery slots, security assurance, drop off points). These service and contractual constraints have a bearing on how particular packages are handled, and indeed, the size of vehicle or vetting of the driver required.

This is an industry that very much competes on price, so efficiency is critically important, and profit margins can be low [8]. There is considerable mutual distrust between rival operators and fierce competition in the marketplace.

However, it is not true to say that cooperation cannot exist, especially in contexts where it is more efficient or cheaper to do so, for example, in congestion or emissions charge areas. In fact, neutral third party businesses or areas where restrictive practice mandated by legislation (e.g. emission or congestion charges) can be particularly effective for steering the market.

\section{The impact of technology}

Technology and data is critical to this industry. From our early field studies it is clear that technology plays a huge role in the day-to-day operations of freight traffic. Parcels are tracked throughout their journey to ensure service levels and delivery guarantees are maintained. 'Parcel manifests' provide detailed tallies of the parcels that need to delivered and collected, are computer generated and essential for both the depot managers, loaders, and delivery drivers. For companies handling larger or routine commercial loads, these are crucial for capacity planning and balancing of loads across vehicles.

Handheld and in some cases wearable laser scanner units, track parcels as they are loaded, delivered, or returned (Figure 1). Technology can also have a role in the vehicles itself, potentially allowing drivers to accept or reject collections, update manifests and query locations.

Increasingly, official devices are supplemented by satellite navigation and personal mobiles that are augmenting practices in various ways.

\section{The importance of people}

Whilst digital systems are essential to the job, and it might be tempting to strive for efficiency improvements through more automation. Our fieldwork so far has uncovered 
myriad ways in which day-to-day job performance is made more efficient due a wealth of local and tacit knowledge that the more experienced workers in the freight traffic industry have developed over their years of employment. There is an enormous gap between the most effective drivers and those with less experience, and this normally translates fairly literally into pay and incentives. These observations echo those of Baudel et al., in particular how there is a need for round optimization to be tailored to each driver and delivery context in order to be effective [2]. We would note however, that route planning software is not typically used in the inner city services we have observed, since it is unable to generate routes that are as effective as the strategies drivers choose for themselves. Even here, there is a very significant difference in the performance of the drivers due mainly to knowledge and experience.

- Loading optimisations. In the case of some carriers, the delivery drivers load the parcels themselves. At this point, local and tacit knowledge of routes can prove highly advantageous as it gives the more experienced driver the ability to organise their load to match their route order.

- The roads. An in-depth knowledge of the roads, their current state, the maintenance, the patterns of congestion on roads at certain times of day (e.g. avoiding areas with schools at certain times of the day, knowing what days particular business are open).

- When to walk. A critical realisation we didn't anticipate, has been that especially in busy city locations, drivers find it much more effective to walk and deliver multiple parcels on foot. Knowing where to stop to maximise access to multiple delivery points, rather than attempting to drive to each destination, transforms delivery speed.
- Stopping places and parking restrictions. While there are tools (e.g. Parkopedia ${ }^{1}$ ) and open data sets (e.g. Local/Municipality provided data ${ }^{2}$ that can tell you where it's legal to stop and park the vehicle or whether the street is a Controlled Parking Zone (CPZ) or not, they can't tell you how lenient the parking attendant is on a particular route. Something as small as knowing whether a parking attendant will ticket your vehicle is enough to help give drivers the edge when it comes to parking their van so that they are able to deliver the most parcels on foot.

- Personal relationships. Related to this, drivers often learn and build trust relationships with the people to whom they deliver regularly. Regular collection points can be avoided by texting or calling ahead, if there's nothing to collect today.

This tacit knowledge, gained in part through experience of delivering on the same set of rounds, is known as "the bible". This is particularly problematic given the large amount of staff churn in the industry. A large volume of knowledge and expertise sits in the heads of the drivers of couriers and freight delivery trucks and vans. There currently isn't any way to capture and share this information.

\section{Discussion}

What has become clear to us from early fieldwork and data analysis, is that there is much to be gained from capturing and sharing some of the successful practices from more experienced drivers, and making this knowledge more transferable. Tacit knowledge is a huge advantage when it comes to the scheduling, loading and deliveries of parcels

\footnotetext{
${ }^{1}$ http://en.parkopedia.com, Last Accessed January 2017

${ }^{2}$ http://www.southwark.gov.uk/parking/ find-somewhere-to-park/parking-map), Last Accessed January 2017
} 
in the urban environment. Through our early ethnographic work in freight depots and on delivery rounds it becomes obvious that the disconnected digital systems present barriers to success for inexperienced depot workers and delivery drivers due to manifests and routes being dynamically optimised by those with local and tacit knowledge of the city scape (e.g. roads, build, routes) and businesses that are delivered to. Potentially significant improvements can be made by making it easier to share and learn from the experience of others.

We believe that there is potential for sharing capacity between services (cf. the Freight Traffic Controller), in at least as much as delivery rounds overlap in time and space. Our analysis is far from complete, but we have been able to observe vehicles returning to locations, sometimes multiple times in the same day. Multiple operators (including but also extending to service vehicles and deliveries far beyond parcel services) routinely deliver to the same streets. Sharing this load capacity could, we believe, have very significant benefits for reducing congestion, and emissions. This will require new open standards and systems for enabling operators to work and plan together in real-time. Some freight will require high assurance, or bulky and heavy items will require specialist vehicles-especially in B2B services. There is work to be done to demonstrate the remaining potential of remultiplexing these freight flows and demonstrating the potential in accessible ways.

However, it is equally clear that this is a complex domain with several significant barriers to overcome. Most challenging perhaps, is that competitors have spent years creating USPs and deliberate intentionally differentiated products. Customers do however drive the demand, and this is an industry that is very sensitive to customer needs. It is clear that applications and portals can unify differentiated services in other domains, could this help shift expectations?

The biggest challenge for us as a community, is to think about how technology can have a role in stemming rather than accelerating demand for ever more immediate delivery of small items. There is currently almost no back pressure from municipalities and policy makers that looks to reduce the amount of freight transport on UK roads. The demand for domestic goods, food and on-demand services delivered at convenient times to workplaces and domestic addresses is further affecting how freight carriers are delivering throughout the day, with the only real worry being congestion and fuel costs.

With applications and businesses increasingly providing next day, and within the hour delivery at very low costs (or even free) for the good of urban space, the health of citizens and the environment it is paramount that technologists intervene and consider how to begin throttling the amount of throughput on our nation's road networks. Through technologically mediated study and intervention we can begin to measure the current state of freight transport, understand the roles that ICT and communication can play in redesigning freight traffic, and redevelop our urban environments based upon data and new tools for modelling urban environments.

\section{Conclusions}

To help realise the research area in $\mathrm{HCl}$, we have focused on last mile deliveries and the people and work inside these services. We've shown that there are a number of human-centred factors that can influence the development of socio-technical solutions such as the FTC. Through technologically mediated study and intervention we can begin to measure the current state of freight transport, 
understand the roles that ICT and communication can play in redesigning freight traffic, and redevelop our urban environments based upon data and new tools for modelling urban environments. The authors wish to begin a discussion with $\mathrm{HCl}$ to help maximise the impact of human-centred research on smart logistics.

\section{Acknowledgements}

We would like to acknowledge the FTC 2050 consortium (http://www.ftc2050.com) and our partners: Gnewt, TNT, DX and TfL. We thank our funder, Engineering and Physical Sciences Research Council (grant ref. \#EP/N02222X/1). The funder had no involvement in the study design, the collection, analysis and interpretation of data, the writing of the paper, or the decision to submit the paper for publication. The authors thank the FTC 2050 project manager, Karen Ghali, for study coordination and administration.

\section{REFERENCES}

1. Julian Allen, Tolga Bektas, Tom Cherrett, Adrian Friday, Fraser McLeod, Maja Piecyk, Marzena Piotrowska, and Martin Zaltz Austwick. 2017. Enabling the freight traffic controller for collaborative multi-drop urban logistics: practical and theoretical challenges. (2017). http: //www.ftc2050. com/papers/FTC2050_TRB2017. pdf.

2. Thomas Baudel, Laetitia Dablanc, Penelope Alguiar-Melgarejo, and Jean Ashton. 2016. Optimizing urban freight deliveries: from designing and testing a prototype system to addressing real life challenges. Transportation Research Procedia 12 (2016), 170-180.

3. Gerardo Carpentieri. 2015. Smart and Sustainable Logistics for a Competitive Europe. (2015).
4. Laetitia Dablanc. 2007. Goods transport in large European cities: Difficult to organize, difficult to modernize. Transportation Research Part A: Policy and Practice 41, 3 (2007), 280-285.

5. Department for Transport. 2015. Transport Statistics Great Britain 2015. (2015). https :

//www.gov.uk/government/uploads/system/uploads/ attachment_data/file/489894/tsgb-2015.pdf, (accessed, January 2017)

6. Department for Transport. 2016. Transport Statistics Great Britain 2016. (2016)

https://www.gov.uk/government/uploads/system/ uploads/attachment_data/file/576113/ tsgb-2016-print-ready-version.pdf, (accessed, January 2017).

7. IMRG. 2015. MetaPack UK Delivery Index Report, September 2015. (2015). https:

//www. metapack. com/wp-content/uploads/2015/10/ MetaPack-September-2015-Delivery-Index-August-2015. pdf, (accessed; January, 2017).

8. M Pooler. 2017. Online orders boost UK parcel market, Financial Times, Jan 5, 2016. (2017).

https://www.ft.com/content/

85c03ea8-b3ab-11e5-b147-e5e5bba42e51, (accessed, January, 2017).

9. Transport for London. 2015. Travel in London: Report 8. (2015). https://tfl.gov.uk/cdn/static/cms/ documents/travel-in-london-report-8.pdf, (accessed, January, 2017). 